INTERNATIONAL JOURNAL OF MULTIDISCIPLINARY RESEARCH AND ANALYSis

ISSN(print): 2643-9840, ISSN(online): 2643-9875

Volume 04 Issue 02 February 2021

DOI: $10.47191 /$ ijmra/v4-i2-12, Impact Factor: 6.072

Page No.- 181-192

\title{
Application of Geospatial Techniques for Hydrological Modelling
}

\author{
Bhanu Pratap Singh ${ }^{1}$, Pradeep Srivastava ${ }^{2}$, Ayushi Trivedi ${ }^{3}$, Deepesh Singh ${ }^{4}$ \\ ${ }^{1}$ M.Tech., School of Biochemical Engineering, Indian Institute of Technology (BHU), Varanasi \\ ${ }^{2}$ Professor, School of Biochemical Engineering, Indian Institute of Technology (BHU), Varanasi \\ ${ }^{3}$ Research Scholar Soil \& Water Engineering, Jawaharlal Nehru Krishi Vishwa Vidyalaya, Jabalpur \\ ${ }^{4}$ Assistant Professor, Department of Civil Engineering, HBTU, Kanpur
}

\begin{abstract}
Geospatial Applications offer a digital illustration of watershed physical characteristics utilized in hydrologic modeling. This paper sums up past endeavors and current patterns in use advanced package of land models and GIS to perform hydrologic investigations. Three strategies of geographic data storage are discussed: formation or grid, triangulated irregular network, and contour-based line networks. The machine, geographic, and hydrologic aspects of every data storage methodology are analyzed. The utilization of remotely perceived information in GIS and hydrologic modeling is reviewed. Borne parameter, physics-based, and hybrid approaches to hydrologic modeling are mentioned with relevancy their geographic information inputs. Finally, many applications areas (e.g., flood plain geophysical science, and erosion prediction) for GIS geophysical science are delineated.
\end{abstract}

KEYWORDS: Geo-Spatial Technology, Remote Sensing, Digital Elevation Models, Geophysical Sciences

\section{INTRODUCTION}

The geospatial technology has vast potential in water resources studies. It's been applied in geophysical science since the launch of Landsat series satellites method back within the 1970's. Geospatial technology will offer data on virtually each aspect of geophysical science either directly or indirectly (through modeling approach exploitation remote sensing inputs) (Bhavsar, 1984; Bastiaanssen, 1998). The estimation of the foremost basic parameters of geophysical science comparable to rain, water body, snow cover, soil moisture may be done simply through remote sensing (Thakur et al. 2017). The hydrological processes akin to evapotranspiration, infiltration, interception, soil wet and runoff (rainfall-runoff \& snowmelt runoff) will more be simulated through hydrological modeling incorporating remote sensing inputs.

Further, at this time the scholars are being instructed the easy definition of the watershed, however, with the assistance of geospatial technology the scholars will delineate the watershed for any region by process the Digital Elevation Models (DEM) produced through remote detecting data. Further, remote detecting inferred DEMs might be used in discovering open channel power through pressure, stream morphology, water conveyance framework, and so on. Likewise, it's a fundamental job in understanding urban hydrology too much the same as even think about storming channel arrange investigation, storm waste overflow estimation, water conveyance, and so forth.. Advanced hydrology topics akin to glacial lake outburst flood, dam break analysis, etc. may be created easier for the scholars through remote sensing within the geospatial domain.

Nowadays, the direct product on hydrological processes akin to Evapotranspiration (ET), soil wet, precipitation, snow water equivalent, etc. generated through remote sensing approach are on the market within the property right at no cost. moreover, numerous geospatial portals or internet services such as Asian country Water Resources data system, Bhuvan, etc. provide helpful data handling the basin boundary; location of the dam and their bathymetry; data of agricultural command space development, flood hazard mapping, basic inputs for hydrological modeling, etc. the scholars will utilize these product to hold out their individual comes of graduate and post-graduate level.

Moreover, such datasets and services are terribly helpful for standardization and validation of their study results. the combination of those two subject can improve the understanding of the scholars as they'll visualize the results of the hydrological method within the geospatial domain akin to simple analysis on the amendment in water body unfold with time, change in snow cowl over an amount of your time, flood inundation, flood modeling, hydrological processes modelling. Therefore, it can be over 


\section{Application of Geospatial Techniques for Hydrological Modelling}

that there's a pressing would like of change and incorporating the utilization of geospatial technology in water resources subjects, for overall understanding and development of the student.

\section{GEOPHYSICAL WATERSHEDS}

It's a drainage basin enclosed by ridge line or divide line, an area from which runoff flows past a single point into a stream. Here Land, Water and the Vegetation are important natural resources and is a basic unit of food, fuel, fodder, and livestock. Development is not only confined only to agriculture land, in this approach but covers the starting from ridge lines to the outlet of the domestic sewerage terminal or natural streams. Planning depends on their scientific delineation.

Although the concept of watershed, a planning unit for development of water and land resource is available since very long time but its approach gained importance in late 1970's. The goals of watershed can be aptly described by the expression POWER given below:

$\mathrm{P}=$ Production of food 'fodder, fuel, fruit, fiber, fish, milk' on sustainable basis.

i. Prevention of floods, soil and water erosion

ii. Poverty elimination

iii. People participation

$\mathrm{O}=$ Over exploitation of resources should be minimized

i. Operational practicability of all on farm operations

ii. Overall development of arable and non-arable land

$W=$ Water storage arid its proper management for different purposes

i. Wild animal's protection at convenient place

ii. Wasteland management

iii. Water harvesting for different purposes $E=E$ Eo-friendly system is to be maintained

i. Economic stability

ii. Employment generation

iii. Empowerment of women in decision making

iv. Energy conservation $\mathrm{R}=$ Recharge of ground water

i. Reduction of drought hazards

ii. Recycling of stored rainwater for different useful purposes

iii. Reduction of siltation in multipurpose reservoirs

iv. Reclamation of soil of fragile environment

v. Reallocation of funds according to priority areas

vi. Resource management especially of persons below poverty line

vii. Reduction in regional disparity between imitated and rain fed areas

viii. Rain fed Farming system approach

ix. Restoration of ecological balance

\subsection{Hydrology of Small Watersheds}

Estimation of runoff and sediment from a watershed requires modeling larger components if not the entire hydrological cycle. The variables also known as system parameters which describes the physical state of watershed system are:

i. Size of watershed

ii. Slope and roughness characteristics

iii. Erodibility

iv. Texture of soil

Watershed affecting variables (known as state variables) are:

i. Temperature

ii. Vegetation cover

iii. Radiation 


\section{Application of Geospatial Techniques for Hydrological Modelling}

Rain and litter contributions are input variables, response of system is hydrograph, Pollute- graph comprising of water, sediment and nutrients. Zones that produce storm runoff also yield sediments, plant nutrients, bacteria and other pollutants. An understanding of the storm runoff production indicates the process by which these components reaches streams and also directs the management particles that might be used to regulate the discharge of these materials.

To understand the basis of erosion process, it is necessary to know the various modes of surface runoff generations. In nature, surface runoff is generated by a variety of surface and near surface flow process.

\subsection{Watershed Characteristics}

The following are the major watershed characteristics of great significance:

i. Size of area of drainage basin

ii. Shape of drainage basin

iii. Length of drainage channel

iv. Slope of drainage channel

V. Soil cover complex

\subsection{Water and Soil Conservation Measures}

Cultivation on steep slopes in humid regions without protection measures often causes serious watershed problems resulting not only deterioration of productivity of land "on-site" by water erosion but also aggravation of silting and flood damage "off-site". The problem is further compounded as the cultivators of steep slopes are mostly poor small farmers. The dilemma is always there, on one side the resettlement and changing of land use may not be feasible from socioeconomic standpoint while on the other hand land and water resources of the hilly region are under constant threat by such cultivation.

Steep slopes can be cultivated safely and profitably by applying terracing and protected waterways. Essentially there are 4 types of bench terraces:
i. Level
ii. Outward slope
iii. Conservation bench (outward slope and conservation slope are for semi-arid and arid regions)
iv. Reversed sloped (suitable for slopes between 70 to 300 in humid regions, there are of 6 types)

\section{LINEAR ASPECTS OF DRAINAGE NETWORK}

3.1. Stream order: The first step in drainage basin analysis is the designation of the stream order which is the measure of position of stream in the hierarchy of tributaries. Further classified as:

i. Firstly order streams are those which have no tributaries whereas the largest channel in a basin was assigned highest stream order.

ii. Secondly order streams are those whose tributaries are only of first order.

iii. Thirdly order receives both first and second order tributaries and it also is considered to extend headword to the end of the longest tributary.

3.2. Bifurcation Ratio: The proportion of number of portions of a provided request Nu to the quantity of sections of higher request $\mathrm{Nu}+1$, spoke to by $\mathrm{Rb}$. The bifurcation proportion won't be the equivalent from one request to next in light of variety in watershed geometry yet will in general be a consistent through the arrangement. This perception is the premise of Horton's law of stream numbers which expresses that the quantity of stream portions of each request frames a backwards geometric succession with request number. The bifurcation proportion gives some proportion of stream sections propensity to partition.

3.3. Regular Watercourse Span: The average lengths of streams of each of the different orders tends to approximate a direct geometric series in which the first term is average length of first order stream.

3.4. Total Span of Channel: Total span of all channel is computed by summing the length of all streams reaching.

3.5. Span of Overland Course: One of the most important independent variables affecting both the hydrologic and physiographic development of drainage basins.

3.6. Inter-Basin Length: The maximum horizontal length measured from the basin mouth to the most distant point on perimeter is termed as inter-basin length. 


\section{Application of Geospatial Techniques for Hydrological Modelling}

3.7. Drainage Capacity: The drainage density, is simply the ratio of total segments length cumulated for all orders within a basin to the basin area. Dimensionally this ratio reduces to the inverse of length.

3.8. Continual Channel Conservation: Introduced constant of channel maintenance as the ratio between the area of drainage basin and total length of all channels or it is equal to the charge density. The importance of this constant is that it provides a quantitative expression of the minimum, limiting area required for the development of a length of channel.

3.9. Channel Frequency: Horton defined the channel segment frequency as the number of streams per unit area in a drainage basin.

\section{WATERSHED PARAMETERS}

4.1. Precipitation: Precipitation is defined as liquid or solid water that reaches the surface of the earth. It denotes all forms of water that reach the earth from atmosphere. The usual forms are snowfall, rainfall, hail, frost and dew. All these only the first two are consecutive significant amount of water. The magnitude of precipitation varies in space and time. For precipitation to form:
i. The atmosphere must have moisture
ii. There must be sufficient nuclei present to aid condensation
iii. Weather condition must be good for condensation of water vapor to take place
iv. The product of condensation must reach the earth.

The form of precipitation can be one of the following type:
i. Rain
ii. Snow
iii. Drizzle
iv. Glaze
V. Sleet
vi. Hail

Some of the term and hydrological process connected with weather system associated with precipitation are:
i. Cyclonic precipitation
ii. Orographic precipitation
iii. Frontal precipitation
iv. Convective precipitation
v. Monsoon

4.2. Interception: Interception is precipitation which collects on the plant canopy. It ultimately evaporates back into the atmosphere and is generally lost as far as surface runoff is concerned. However, it represents an abstraction from precipitation and must ultimately be quantified. The 4 primary factors which influence the amount of interception are:

i.Species of vegetation
ii. Growth stage of vegetation
iii. Season of year
iv. Wind velocity

4.3. Surface Retention: This is the water retained on the ground surface in micro depression. Factors which control the amount of surface retention are:
i. Micro-topography
ii. Surface macro slope

The primary physical factor influencing the magnitude of surface retention is the surface micro-relief of the area and any factor which have a bearing on that micro-relief.

4.4. Surface Detention: In this water temporarily detained on the surface that is necessary required for surface runoff to occur. Therefore, it could logically be considered as an integral part of the surface runoff component rather than a 


\section{Application of Geospatial Techniques for Hydrological Modelling}

separate process.

4.5. Infiltration: Infiltration is defined as the entry of water from the surface into the soil profile. Infiltration is the key process at the land surface which must be carefully considered in the models for describing the hydrology of the watershed. Water may infiltrate immediately from rainfall into the soil profile or it may flow into the temporary storage and infiltrate later. Horton (1931) defined infiltration capacity as the maximum rate at which a given soil in a given condition can absorb rain as it falls. It is the infiltration capacity of the soil that determines for a given storm, the amount and the time distribution of rainfall excess that is available or runoff or surface storage. The major controlling factors are:
i. Soil Properties
ii. Initial Water Content
iii. Rainfall Rates
iv. Surface Tealing And Crusting
V. $\quad$ Layered Soil
vi. Movement And Entrapment Of Soil Air

4.6. Evapotranspiration: Evaporation and transpiration commonly called Evapo- transpiration (ET) is the conversion of water to vapor and the transport of that away from watershed surface into the atmosphere. The ET varies both in space and time and mainly depends on available water and solar radiation. Estimation of ET require to consider 3 sets of variables in a vertical water budget within a system as:
i. Determination of potential ET
ii. Plant -water related characteristics
iii. Soil -water related characteristics

ET varies from place to place in a watershed and also varies throughout the day. Spatially average daily ET values may be used for hydrologic models.

47 Soil Moisture: Soil moisture is the term applied to the water held in the soil by molecular attraction. The forces acting to retain water in the soil are adhesive and cohesive forces. These forces act against the force of gravity and against evaporation and transpiration. Thus, the amount of moisture in the soil at any given time is determined the strength and duration of the forces operating on the moisture and the amount of moisture initially present.

48 Stream Flow: Most hydrological analysis involve runoff from a drainage area, and hence its measurement is of vital importance. Stream flow data are collected primarily for hydrologic studies. Stream flow measurements are used to develop physical or statistical relation between other variable and runoff volume or peak discharge.

49 Base Flow: Base flow is the flow to the channel of a watershed that comes from ground water or spring contribution and may be considered as the normal day to day flow. The base flow component is composed of water that percolates downward until it reaches the groundwater reservoir and that flows to surface streams as ground water discharge. The release period of ground water accreted due to storm depend on the size of basin.

410 Erosion And Sediment Yield: Estimates of watershed sediment yield are required for solution of a number of problem:
i.Design of dams and reservoirs
ii. Transport of pollutants
iii. Design of soil conservation practices
iv. Design of stable channel
v. Design of debris basin
vi. Depletion of reservoirs, lakes and wetlands
vii. Determination of the effect of basin management
viii. Offsite damage evaluation
ix. Cost evaluation of the water resource project

\section{CURRENT ISSUES AND CHALLENGES IN HYDROLOGY}

It is not shocking, therefore, to check perennial surges of promotion attend water resource problems as chronic issues persist 


\section{Application of Geospatial Techniques for Hydrological Modelling}

and hard new patterns emerge. Over the past decade, variety of challenges are highlighted by governmental and nongovernmental water organizations, consultative bodies, resource-management establishments and therefore the scientific community. These embrace ensuring: a secure water supply - for drinking and sanitation, irrigated agriculture, aquatic ecosystems associated economic development; the event and maintenance of an infrastructure to manage risks related to floods, droughts and pollution events; and association across sectors and boundaries; and making public awareness and understanding of the restrictions of the resource.

However, what is also the foremost important burgeoning challenge related to water resources has received comparatively minor attention, i.e. making certain the adequacy, consistency and semi-permanent maintenance of high-quality hydrological observations. Despite the precise water concern, effective and economical watching of the amount and quality of the resource (on the surface, within the ground, at associate appropriate frequency and for an appropriate time period) could be a requisite. This text highlights a number of the lot of notable issues presently facing National Services that collect and manage hydrological information. For several National Services, these problems are significantly worrisome as a result of the distinctive role they play within the development and validation of latest watching approaches, still as within the management of watching networks among their various nations.

5.1 Network Declines: The foremost wide mentioned and documented challenge facing hydrological observations in recent years has been the persistent and pervasive trend toward declining networks. It's additionally a tangle that impacts alternative challenges represented in resulting sections. Widespread business constraints at the national level, in addition to political and institutional instability across the country and regionally, are usually cited because the cause.

Nevertheless the matter isn't distinctive to poor or developing nations. Indeed, it's a big issue in several developed countries. These are precisely the stations most required for important flood and low-flow frequency analyses, still as for evaluating hydrological patterns and trends within the context of climatically variability and alter. These are perturbing patterns as a result of, although stations will be re-opened or replaced at some purpose within the future, the break in semi permanent observations adversely affects our ability to develop strong statistics that are dependent upon consistent multi-decadal to centennial records.

Clearly, methods have to be compelled to be developed and enforced that preserve long-record hydrological stations in areas of significant national and international interest which expand the quantity of stations in areas that presently don't seem to be monitored or that are inadequately monitored.

5.2 Matching the information Collected to Their meant Use: Hydrological data are used for several functions, from hazard warning and water prognostication to stuff transport and aquatic surround analysis. Several of the information have intrinsic utility, as collected, in several applications. Watercourse stage measurements at specific locations in real-or close to time period, as an instance, are utterly suited to operational flood prognostication at or close to those locations. Variety of applications, however, are unnatural to use information that don't seem to be optimum for the meant purpose.

A vexing current example is that the use of mean daily and mean monthly discharge at stations having under thirty or forty years of record within the analysis of semi-permanent trends which will be involving climatically amendment. Sadly, only a few stations worldwide give such records. this is often additionally true for analyses of changes within the frequency and severity of floods and droughts that need specific data on precipitation and discharge extremes, monitored consistently and systematically over terribly while periods in a very big selection of hydro climatically settings. Alternative issues, cherish non-point supply contamination of streams thanks to nitrate, pesticide, and sediment-laden runoff will need hourly information as a result of such contamination is closely related to the temporal arrangement of storms and resultant runoff.

Moreover, problems cherish these are difficult by the extra would like for information at various spatial scales, as a result of land use and farming practices exert a marked influence on the native variability in stuff loading. Currently, water-quality constituents are solely sparsely monitored in each house and time, as this sort of watching is usually rather dearer than stream gauging, as a result of samples should be with chemicals analyzed in laboratories. Clearly, therefore, matching the information being collected to the matter being addressed needs empiric systems that operate systematically and faithfully over very long and really short time-scales and at massive to tiny space-scales: a frightening and dear prospect.

5.3 Increased Hydro Chemical And Hydro Biological Monitoring: As understanding of the interactions of physical, chemical and biological processes in water has dilated over the past four decades, thus too has the quality of the watching of those processes. Whereas, before the first Nineteen Sixties, hydrological watching targeted totally on stream flow, sediment transport and groundwater levels, the stress has shifted these days toward water quality because the issues related to contamination became a lot of manifest. This shift has dramatically dilated the quantity of variables being ascertained, significantly 


\section{Application of Geospatial Techniques for Hydrological Modelling}

of phylogeny compounds in water and sediment, still as aquatic organisms.

Progressively, National Hydrological Services and connected environmental services are being charged with providing empiric information to support national water-quality laws, restoration of aquatic ecosystems compact by agriculture and therefore the promotion of water resources property (National analysis Council, 2004). Providing the type of increased chemical and biological observations necessary to satisfy these demands remains a challenge. Moreover, innovative techniques that are scaled befittingly for application to subcontinental watersheds are needed and, sadly, such large-scale watching methods don't seem to be nevertheless mature enough to satisfy several current issues, a lot of less new ones.

5.4 Information Deposit and Dissemination: The increasing volume and kinds of hydrological data being transmitted to, and keep in, information centers progressively in real-or near-real-time is making vital issues involving data deposit and dissemination. Typically, these arrangements have long historical precedents and lead to wide variable capabilities for supporting user desires and with completely different rules for creating information on the market. Invariably, researchers and alternative information users realize it troublesome to find and procure consistent and comparable data, even among one country.

As long as the prospects are low for seeing a dramatic amendment during this state of affairs within the close to term, it might be significantly useful if National Hydrological Services may develop on-line portals to their numerous hydrological databases. No less a challenge is that the free and unrestricted dissemination of hydrological information and knowledge. National information policies usually limit data dissemination to regional or international data centers and, in several instances, need the information Centre to get approval before providing data to requesting parties.

The exchange of hydrological information is more difficult by non-standardized data formats and exchange protocols, still as incompatibility in info standards and modes of access. With an eye fixed to removing barriers to information exchange, Thirteenth World meteorological Congress (1999) adopted a resolution on the exchange of hydrological data and product that gives a global reference in shaping and implementing policies for the exchange of knowledge and knowledge.

5.5 Accounting for Uncertainties in ways and Networks: Quantifying the uncertainty in hydrological predictions and accounting for this uncertainty in resulting decision-making are a vital aspects of operational modelling and analysis. The first sources of modelling uncertainty are the information, in terms of their spatial and temporal fidelity and representativeness, and therefore the modelling approach itself.

Thus, accounting for the uncertainties related to watching ways and networks is important to reducing prophetical uncertainty. As long as hydrological prognostication depends heavily on measurements of multiple hydrological variables taken long periods of your time, decreases within the size and density of watching networks (as noted earlier) can essentially increase forecast uncertainty. This points to a transparent would like for procedures to rescue and augment information. there's additionally a growing would like for ways to validate and estimate the uncertainty of remotely detected information, as these are getting progressively necessary contributors to hydrological analyses.

\section{GEOSPATIAL TOOLS AND TECHNIQUES}

A Geographic information system, or GIS, permits us to look at and analyze geographic knowledge so as to raise interpret and perceive its significance. Users of hydrologic models realized early on that by group action GIS and hydrologic modeling they would have a strong tool for evaluating knowledge. ab initio used for such map-based approaches as delineating watershed boundaries and static representations of surface water bodies, GIS in hydrologic modeling had big to incorporate advanced landwater interactions and also the combination of GIS datasets with simulation modeling.

GIS provides representations of those spatial options of the planet, whereas hydrologic modeling worries with the flow of water and its constituents over the land surface and within the subterraneous atmosphere. Groundwater vulnerability to contamination from the land surface has become a very important space of hydrogeological analysis. There's additionally a desire but for additional intensive evaluations of groundwater vulnerability that may facilitate guide land coming up with and management at regional scales.

Hydrologic models are mathematical illustration of the flow characteristics. These models are productive in addressing time variation presumptuous uniform spatial properties. There are 3 main basic problems in geophysical science that are necessary to model to know the issues moon-faced by the environmental system. These problems are:

i. $\quad$ Pollution management and mitigation for each groundwater and surface water.

ii. Water Utilization for water for municipalities, agriculture and business and also the competitor demands for in stream water use and life environs.

iii. Control and mitigation. 


\section{Application of Geospatial Techniques for Hydrological Modelling}

6.1 Geospatial Techniques for Hydrology Modelling: GIS and hydrologic modeling have been used along to model surface runoff, delineate water channels and watersheds, and calculate emptying areas and volumes for native systems. they need also been combined to tackle broader national and global based mostly issues in water resources management equivalent to the impact of worldwide temperature change on aquifers within the western us additionally as access to scrub water in developing countries.
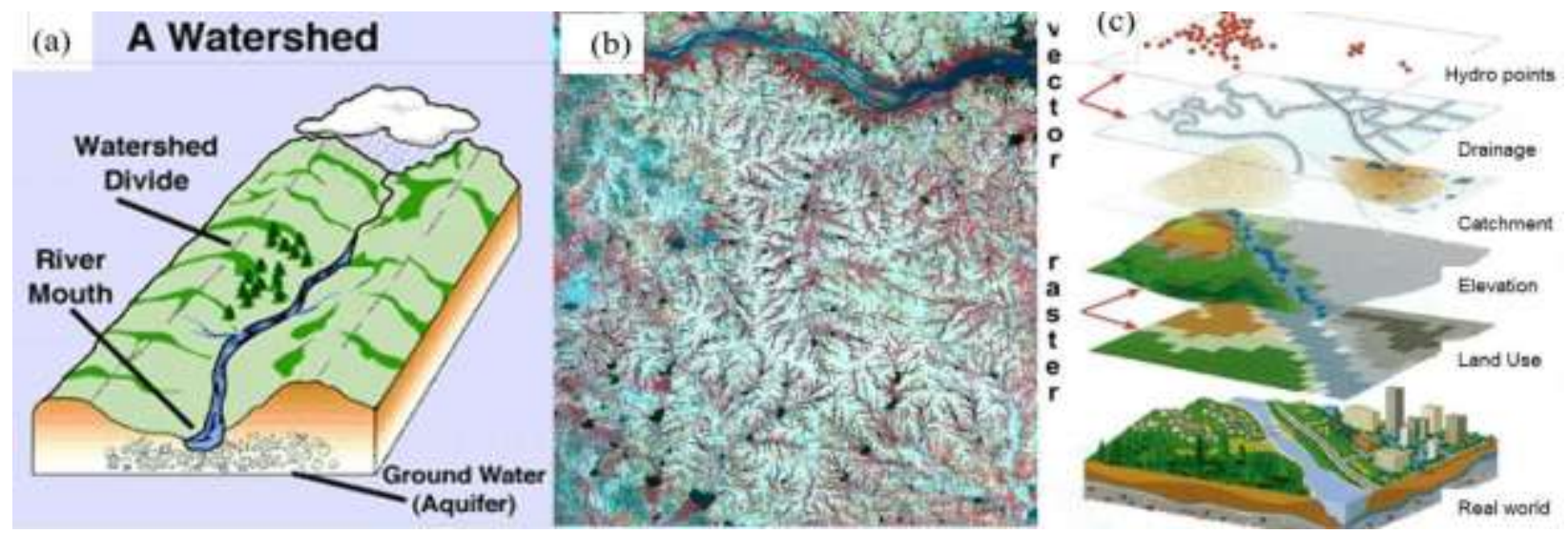

Figure 1: Hydrology modelling through Remote Sensing. a) A typical representation of watershed b) An example of watershed as seen in remote sensing multispectral image color composite c) Integration of vector and raster layers in GIS for representation of real world scenarios and hydrological features

(Source: Indian Institute of Remote Sensing)

6.2 Emphasizing GIS Modelling: Modeling attracts to bigger or lesser degree upon the geographic tradition that geophysical science, construction and watercourse system move closely and nonchalantly in time and house. The weather of hydrological modeling predate GIS by quite a century. GIS's are extremely specialized management systems for spatially distributed knowledge. Chow et al. (1988) offered a taxonomy of hydrological models supported the randomness (deterministic/ stochastic), special variation (lumped/ distributed; house independent/space dependent) and time variation (steady flow/ unsteady flow; time independent/time correlated) - thereby drawing the eye to the polar position of the spatial dimension explored the many potential applications of linking GIS with the hydrological models:

i. Hydrological Assessment to represent hazard or vulnerability (through weighted and summed influences of serious factors instead of through physical laws)

ii. Hydrological Parameter Determination, whereby the GIS provides inputs to the model in terms of parameters equivalent to surface slope, channel length, land use and soil characteristics.

iii. Hydrological Modeling among the GIS, provides possible time snapshots or temporal averages are concerned, not time series.

iv. Linking the GIS and hydrological models to use the GIS as an input and show device, as well as real time method watching if the mandatory (remotely sensed) observations are out there

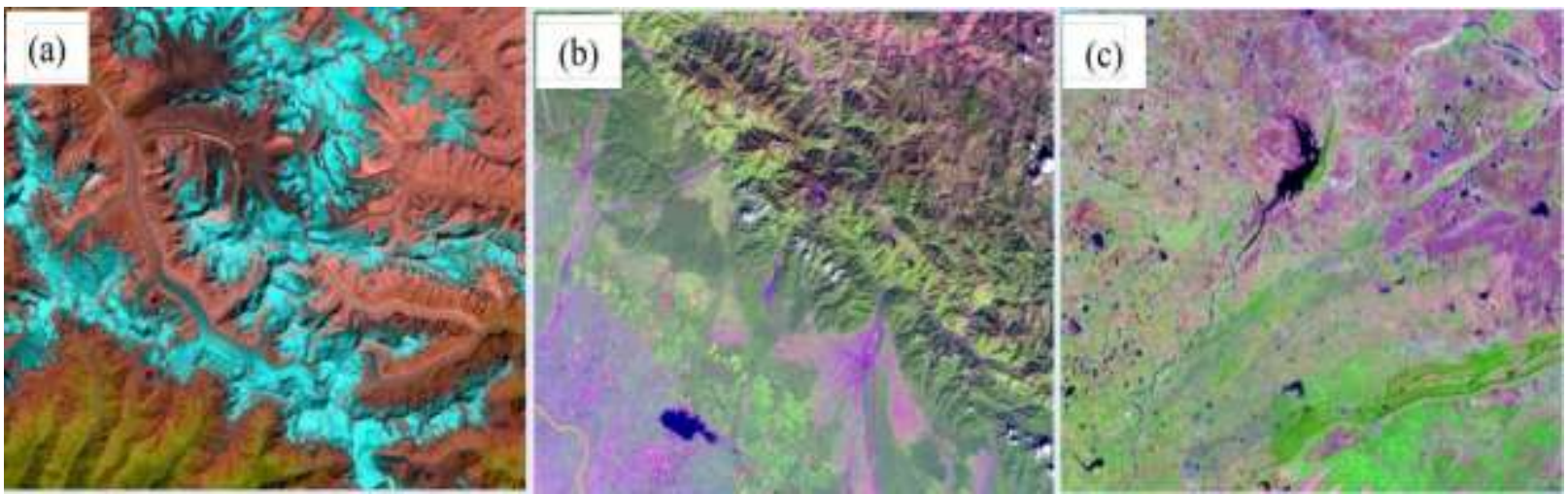

Figure 2: Hydrological complexities as seen in RS data of various regions. a) Remote sensing images of snow-glacier dominated Gangotri area. b) Forested and Tarai agriculture/urban regions of Nainitital and Rudrapur, UK. c) Central India near Bisalpur reservoir and surrounding area dominated by small man made water bodies and agricultural area.

(Source: Indian Institute of Remote Sensing) 


\section{Application of Geospatial Techniques for Hydrological Modelling}

\section{STRUCTURE FOR GIS APPLICATIONS IN HYDROLOGY}

However relate these set of assumptions as a spectrum of serious role of GIS, with full linkage to modeling being seen because the final expression of GIS contribution, however consistent with him these set of assumptions would be deceptive the worth of GIS not essentially determined by the extent to that it's on top of things of the processes involved, the role of GIS is damaging. Any the info has been replaced by GIS because the desegregation core of company information handling, which can any upgrade by network computing capability. GIS integrates totally different components like automatic mapping (AM), facilities management (FM), remote sensing, land data systems (LIS) and special statistics, conjointly at constant time it function associate degree input to the management data systems (MIF) within the company domain and modeling / management systems in the analysis domain. Because the company sector emphasizes the info as the key to the management information systems, within the same means the info model that is that the key to the GIS modeling in hydrology last.

"It is perhaps true that the issue most limiting hydrologic modeling isn't the power to characterize hydrologic processes mathematically, or to unravel the ensuing equations, however rather the power to specify values of the model parameters representing the flow atmosphere accurately. GIS can facilitate overcome that limitation."

7.1 Application Domains of DEM In hydrology: Digital Elevation Models are utilized in variety of sub-domains in hydrology. Varied hydrological applications is driven by completely different users accessing constant pool of knowledge. As a result the structure of the information that supports the GIS, quality of the info and therefore the means during which the information is managed lie at the guts of development of the many GIS applications. The DEMs have well-tried to be terribly economical in extracting the hydrological knowledge from the DEM by analyzing completely different geographic attributes (elevation, slope, aspect, relief, curvatures) for modeling functions. There are variety of models developed in past that has been helpful one by one and combined applications in varied combos. DEMs have probably well-tried to be a valuable tool for the geography parameterization of hydrological models particularly for emptying analysis, hillslope hydrology, watersheds, groundwater flow and stuff transport etc.
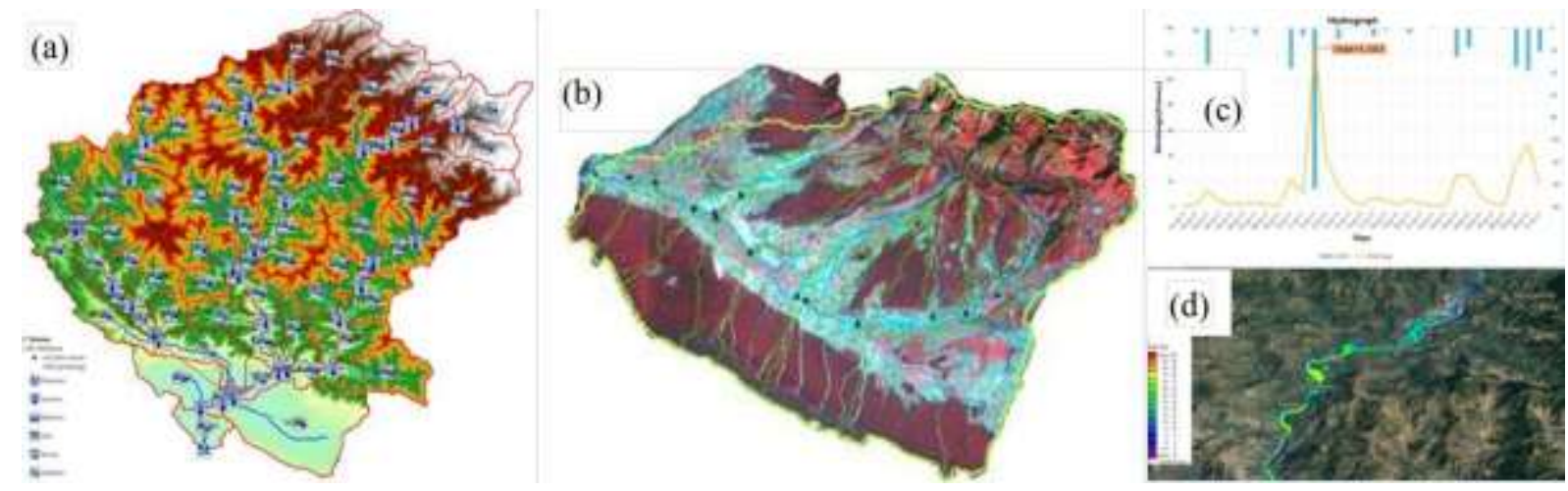

Figure 3: Hydrological modeling and results a) HMS model set up for Yamuna basin; b) SWAT model for ASAN watershed c) Hydrological modeling results for peak flood of 12 July 2017 in Dehradun city d) PMF flood inundation scenario for Alakhnanda river from Rudraprayag to Devprayag river, Uttarakhand based on 1-D HD model.

(Source: Indian Institute of Remote Sensing)

Figures 1, 2 and 3 shows the utility and applications of RS-GIS in hydrological modeling, role of remote sensing to captures patiotemporal variability of various land use and land cover features in various hydro-climatic and topographical regions of India and example setup and results of various popular hydrological and hydrodynamic models, which rely heavily on geospatial technology based thematic and hydro-meteorological data for its simulations and model outputaccuracy

\section{HYDROLOGICAL APPROACHES IN SPATIAL CONTEXT}

8.1 Rainfall-Runoff Models: Prediction of surface runoff is one amongst the foremost helpful hydrologic capabilities of a GIS system, the prediction could also be accustomed assess or predict aspects of flooding, aid in reservoir operation, or be accustomed aid within the prediction of the transport of water-borne contaminants. The kinds of models that are applied with a GIS are going to be classified as lumped parameter, physics primarily based (implying full spatial distribution and modeling for runoff connected attributes), or some combination of both. 


\section{Application of Geospatial Techniques for Hydrological Modelling}

8.2 Lumped Parameter Models: The basic unit of a lumped parameter model is generally taken to be a sub-basin of the whole watershed being thought-about. Every sub- basin is taken as a hydrologic response unit, in order that all attributes should be averaged or consolidated into unit-level parameters.

i. $\quad$ Physics primarily based Models

ii. Hybrid Models

8.3 General Indices: In some cases complete rain runoff response needn't be delineated to produce the required hydrologic engineering data. General indices of the tendency to supply runoff could also be decent. Deciding is supported easy maps of piece of ground properties. Further, the map knowledge made is saved for future use in a very actual rain runoff prediction if they're keep in a type acceptable to the model to be used.

i. Imperviousness

ii. Natural Land Cover

8.4 Watershed Delineation and Stream Networks: The information gained within the method of deciding the trail of runoff and therefore the limits of a watershed is helpful in each hydrologic and water quality. Many systems are developed for these functions, with the tip results of the GIS manipulations being watershed boundaries and stream ways. As delineated antecedently a raster-based method known as region growing .used to extract water path knowledge. TIN system and steepest descent and ascent to delineate drain-age boundaries, and verify flow ways and stream networks, it notably suited to steepest descent ascent owing to the uniform slope on every triangle aspect.

\section{END USE OF SPATIAL HYDROLOGY}

The prediction of runoff history is also only one element of prediction of the results of watershed runoff. The runoff will cause erosion, flood injury, and transport contaminants. Usually the accuracy of the runoff model is settled by the accuracy needed by a model secondary to the hydrologic model. The resolution of the DEM can also be determined by necessary accuracy of the tip model. The subsequent printed studies are samples of finish uses of GIS hydrologic predictions. The applications cited are indicative of varying prospects, however the list is by no means that thoroughgoing.

9.1 Floodplain Management and Flood prediction: A grid cell knowledge bank was employed to assess flood injury using HEC-1 and therefore the profile program HEC-2. Plane figure knowledge was used, however it absolutely was reborn, grid cell format before application. Water quality and erosion modeling were additionally thought-about within the framework of a flood event. Spud and Hoiberg (1991) additionally use a GIS for flood injury assessment, however the stress is on continued management. Thus, single event simulation is a smaller amount necessary and general indices are of larger use. DLG knowledge was used as a result of it absolutely was the foremost correct on the market data bank.

9.2 Erosion Prediction/Control: Using a TIN and therefore the kinematic differential equation, Eli and several other investigators applied GIS methodology to surface deep-mined lands. The Universal Soil Loss Equation (USLE) was wont to predict erosion. The USLE doesn't need runoff data, solely data conceding soil, land cover, downfall intensity, and topographical properties. Thus the USLE predicts erosion potential, however the kinematic wave and erosion predictions are used along to work out suspended sediment masses. During this approach, it's clear that erosion prediction and water quality prediction are connected.

9.3 Water Quality Prediction/Control: Air and water are the first carriers for contaminants within the terrestrial environment. Any kind of moving water may be a potential transporter of pollution. The movement is doubtless smart therein it will disperse materials; however irrespective of why data is required regarding contaminant movement, information of the magnitude and temporal distribution of flow is important for correct prediction of the movement.

9.4 Drainage Utility Implementations: Drainage utility applications were mentioned earlier in describing the overall index of p.c impermeability. The info base needed isn't as intensive as alternative applications, as a result of no runoff modeling is performed.

\section{FUTURE OUTCOMES}

Globally there are several challenges wherever combining GIS with hydrologic modeling has been shown to improve results and outcomes. Several areas are beginning to use these tools to safeguard the restricted water resources inside their country and 


\section{Application of Geospatial Techniques for Hydrological Modelling}

across regions. In sub-Saharan continent this mix is getting used to find and improve access to wash drinking water sources. In Turkey it is being used to forecast the potential of groundwater springs. Archeologists are even exploitation GIS and hydrologic modeling of ancient irrigation systems to grasp however communities developed and therefore the reasons they could have declined. They are then putt this data to use in developing irrigation and water use practices that are property. In several places the want for clean and plentiful drink may be a matter of life and death. exploitation the info obtained from GIS and the predictions obtained from hydrologic modeling will offer native likewise as national governments the tools necessary to manage this precious resource for this and future generations.

The use of GIS has grownup exponentially over the years as pc systems have advanced at a wide ranging rate. The simply handiness of GIS knowledge sets adore STATSGO soil data, DEM elevation knowledge, HUC watershed knowledge, and therefore the NLCD land cowl knowledge offer necessary data for the development of hydrologic models. A number of the sooner tries to mix these 2 systems were cumbersome and troublesome to use. The future of GIS in hydrologic modeling is the full integration of each systems.

This new generation of package combines the hydrologic modeling necessary to totally perceive advanced water systems with all aspects of GIS to get, use, visualize and interpret geographic data. wherever at 1st combining GIS and hydrologic modeling may have solely meant an easy map overlay to show the boundaries of a watershed, nowadays there are specific models getting used to see world changes within the water cycle and their effects on the worlds recent drinking water offer. In the long run GIS and hydrologic modeling can continue to be used along to study and perceive the advanced movement of water through the surroundings. These two powerful tools can be used to solve more and more advanced and important water resource issues on a neighborhood, regional, and world scale.

\section{CONCLUSIVE OUTLINE}

From the previous discussions it's clear that GIS's are effectively utilized in a range of hydrologic applications. But the price of implementing a GIS may be vital, particularly once the price of knowledge assortment and manipulation is taken into account. Thus, it's best once the info base may be shared for many connected functions. As an example, a GIS knowledge base assembled for flood statement may even be of use in nonpoint pollution observance. Sadly, the organizations curious about these 2 activities are clearly totally different, and will they attempt to invest in GIS technology, it's not going that they might would like to possess an information base not custom orientating to their application. Once one considers the various potential finish applications of a GIS, from hydrologic predictions to regional resource management, some variety of inter-organizational effort are necessary to share the prices and edges of a GIS.

Part of the matter in acceptance of GIS methodology in geophysical science for on the other hand analysis functions is tied to the custom nature of the many of the applications. Another additional disturbing reason for lack of acceptance is that the lack of clear proof of the prevalence of GIS results to more ancient ways. To the hydrologic engineer, there's very little distinction within the tedium of hand measurements from U.S.G.S. maps and digit king identical data. laptop manipulation of remotely perceived knowledge removes the tedium side, however the inaccuracies of deciphering spectral knowledge once more results in the question of superiority to straightforward manual data entry ways. The question will solely be resolved through a broad based mostly validation study. In the

U.S. such studies have solely been flourishing once undertaken by an administrative unit. A study of such an oversized scope won't probably be undertaken till GIS geophysical science becomes additional wide utilized in the sphere.

\section{REFERENCES}

1 1991. Denver, Colorado Extraction of Geomorphic and Geologic information for groundwater exploration through satellite remote sensing in and around the Wichita Mountains, Oklahoma. Proceedings of the Eighth Thematic Conference on Geologic Remote Sensing, 171-180 (ERIM) Denver, Colorado, Vol. 1.

2 Chouhan D, Tiwari HL and Galkate RV. 2016. Rainfall runoff simulation of Shipra river basin using AWBM RRL toolkit. International Journal of Engineering and Technical Research 5 (3) : 73-76.

3 Mulligan M. 2004. Environmental Modelling Finding Simplicity in Complexity. Department of Geography, King's College London.

4 Abbott, M.B., Bathrust, J.C., Cunge, J.A., O'Connell, P.E. and Rasmussen, J., 1986b. An introduction to European hydrological system - systeme hydrologique Europeen (SHE) Part 2. Structure of a physically based distributed modeling system. Journal of Hydrology 87,61-77

5 Abu El-Nasr, A., Arnold, J.G., Feyen, J. and Berlamont, J., 2005. Modeling the hydrology of a catchment using a distributed 


\section{Application of Geospatial Techniques for Hydrological Modelling}

and a semi distributed model. Hydrological Processes 19,573-587.

6 Agricultural Engineers ISSN 0001-2351. Vol. 47(3):789-803.

7 Bergström, S., 1976. Development and application of a conceptual runoff model for Scandinavian catchments. SMHI RHO 7. Norrköping. 134.

8 Beven, K. J. and Kirkby, M.J., 1979. A Physically Based Variable Contributing Area Model of Basin Hydrology. Hydrological Sciences Bulletin 24, 43-69.

9 Beven, K.J., Kirkby, M.J., Schofield, N. and Tagg A.F., 1984. Testing a physically based flood forecasting model (TOPMODEL) for three UK catchments. Journal of Hydrology 69,119-143.

10 Borah, D. K., Bera, M. and Shaw, S., 2003. Water, sediment, nutrient, and pesticide measurements in an agricultural watershed in Illinois during storm events. Trans. ASAE 46(3), 657-674

11 Borah, D.K. and Bera, M., 2004. Watershed-scale hydrologic and nonpoint-source pollution models: review of application. American Society of

12 Chowdhury A, Jha MK, Chowdary VM (2010) Delineation of groundwater recharge zones and identification of artificial recharge sites in West Medinipur district, West Bengal, using RS, GIS and MCDM techniques. Environ Earth Sci 59:1209e1222

13 D. Das 1996. Environmental appraisal for water resource development proceedings. International conference on disaster Management (ICODIM) 499-507 Guwahati : India, Organized by Tejpur University

14 Dar IA, Sankar K, Dar MA (2010) Deciphering groundwater potential zones in hard rock terrain using geospatial technology. Environ Monit Assess 173:597e610

15 Das D (2000) GIS application in hydrogeological studies.

16 Das D 1990. Satellite remote sensing in subsurface water targeting. Proceeding ACSM-ASPRS annual convention, 99-103

17 Dingman, S. Lawrence, Physical Hydrology, Prentice-Hall, 2nd Edition, 2002

18 Fetter, C.W. Applied Hydrogeology, Prentice-Hall, 4th Edition, 2001

19 Girish Kumar, M., Bali, R. And Agarwal, A.K (2009). GIS Integration of Remote Sensing and Electrical Data for Hydrological Exploration- A Case Study of Bhakar Watershed, India. Hydrological Sciences Journal 54(5)Pp 949-960. http://www.gisdevelopment.net/application/nrm/water/overview/wato0003.htm. Accessed Mar 2010

20 Jain, M.K. GIS Based Rainfall Runoff Modelling For Hemavathi Catchment. Cr/Ar 22/96-97, National Institute Of Hydrology, Roorkee.

21 Jain, M.K. Watershed Modelling With GIS Based Distributed Unit Hydrograph Approach. Cs/Ar 8/97-98, National Institute Of Hydrology, Roorkee.

22 Kothyari, U.C., S.K.Jain,' Sediment Yield Estimation Using GIS', Hydrological Sciences Journal, 46(2), December, 1997

23 Maidment, David R., Ed. Arc Hydro: GIS for Water Resources, Esri Press, 2002

24 Naidu, Dadi (December 2015). "Use of GIS in Hydrological Investigations" (Pdf). International Journal of Interdisciplinary Advanced Research Trends. li (2).

25 Naidu, Dadi (December 2015). "Use of GIS in Hydrological Investigations" (Pdf). International Journal of Interdisciplinary Advanced Research Trends. li (2).

26 Naidu, Dadi (December 2015). "Use of GIS in Hydrological Investigations". International Journal of Multidisciplinary Advanced Research Trends. 2 (2).

27 Rabie, Anas (2014). "Integrating GIS and Hydrology forFlood Risk Analysis".

28 Saraf, A. K.; Choudhury, P. R. (25 Nov 2010). "Integrated Remote Sensing And GIS For Groundwater Exploration And Identification Of Artificial Recharge Sites". International Journal of Remote Sensing. 19 (10). Doi:10.1080/014311698215018.

29 Sarkar BC, Deota BS (2000) A geographic information system approach to ground water potential of Shamri micro-watershed in the Shimla Taluk, Himachal Pradesh. Unpublished Project Report submitted for NNRMS sponsored course on GIS; Technology and Application IIRS, NRSA, Dehradun, India, 24.

30 Trivedi Ayushi, Pyasi SK, Galkate RV. 2018. Estimation of Evapotranspiration using CROPWAT 8.0 Model for Shipra River Basin in Madhya Pradesh. International Journal of Current Microbiology and Applied Sciences 7(05):1248-1259.

31 Trivedi Ayushi, Pyasi SK, Galkate RV. 2019. Impact of Climate Change Using Trend Analysis of Rainfall, RRL AWBM Toolkit, Synthetic and Arbitrary Scenarios. Current Journal of Applied Science and Technology. 1-18. 